\title{
MUDANÇAS SÓCIOCULTURAIS E RECONFIGURAÇÃO DO ESPAÇO URBANO
}

\author{
Chauana Silva Araújo \\ Graduada pela Universidade do Estado da Bahia \\ Liliane Ferreira Mariano da Silva \\ Doutora em Urbanismo, Docente da Universidade do Estado da Bahia \\ Marília Moreira Cavalcante \\ Doutora em Arquitetura e Urbanismo, Docente da Universidade do Estado da Bahia
}

\section{RESUMO}

Na história da sociedade, o surgimento e desenvolvimento das cidades sempre foi marcado pela apropriação do espaço público. Os diferentes atores sociais configuram e modificam o espaço urbano de acordo com o seu modo de viver. Estimativas apontam a cidade do Salvador, com uma população de quase 3 milhões de habitantes, assim como as demais cidades brasileiras, sofre com a crescente violência urbana, por exemplo, segundo o Sistema de Informação Municipal de Salvador (SIM), em 2014 foram registrados 1.749 furtos, e os roubos seguidos de morte foram de 50 (2014) para 64 (2015). O sentimento de medo generalizado por parte significativa da sociedade nas cidades, principalmente nos países da América Latina, vem reforçando as construções de estrutura que denotam sensações de segurança, como muros, paredões, cercas, grandes, entre outros. Esses elementos permitem a criação de dois mundos que muitas vezes não se comunicam, além de ocasionar a morte da vitalidade e degradação dos espaços externos. Em Salvador, registra-se um grande número de aglomerados e condomínios habitacionais arrodeados pelos muros. Diante da magnitude do tema, e a impossibilidade de tratar aqui de todo o conjunto, selecionou-se o "Bloco 83" do Conjunto Habitacional dos Oficias da Polícia Militar - 1 (CHOPM-1), localizado no bairro do Cabula, Salvador, Bahia. A partir da análise do projeto original foi-se reconstituindo a proposta de circulação, área de recreação, sistema viários, centros comunitários e outros aspectos, e as transformações ocorridas ao longo do tempo foram coletadas através de conversas com moradores e do levantamento in loco para mapear, fotografar e avaliar as transformações no uso e ocupação desses espaços comuns. Essa pesquisa objetiva analisar o processo de reconfiguração dos espaços comuns do bloco 83, principalmente, frente aos impactos socioespaciais da violência urbana, além de compreender como essa alteração da morfológica influenciou na dinâmica de crianças e adolescentes.

Palavras-chave: Crianças; Espaço público; Violência; Vitalidade; 


\section{FORMAÇÃO DO ESPAÇO}

A compreensão histórica das transformações do bairro do Cabula até os dias de hoje relaciona-se diretamente com as configurações morfológicas do bloco 83 do Conjunto dos Oficiais da Polícia Militar-1. De acordo com Santos (2008), o espaço é uma um conjunto indissociável composto por objetos geográficos, naturais e sociais, assim como a sociedade que preenche e anima o espaço.

O bairro, segundo Gouveia (2010), passou por quatro processos de configuração espacial, que foram a herança dos antigos núcleos quilombolas, o povoamento inicial através da existência de chácaras destinadas a produção agrícola, a ação do Estado e do capital imobiliário. É possível encontrar lembranças e marcas que remetem a esse período aos processos mais distantes, como os terreiros de candomblé e algumas pequenas chácaras.

As delimitações territoriais até o século XIX eram feitas a partir de freguesias, pequenas unidades eclesiásticas, controladas pela igreja matriz. Segundo Costa (1989), a cidade era dividida em 2 distritos, um urbano e o rural onde o Cabula estava inserido. Esse bairro já foi constituído de fazendas e chácaras de laranjas que abasteciam toda cidade, entretanto, no período de 1940 a 1950, ocorreu uma infestação de pragas que transformou o uso do solo.

O Estado da Bahia enfrentou uma estagnação econômica por conta da falta de diversidade na exportação de produto, passando a depender apenas do cacau, recuperando-se a partir da descoberta do petróleo na década de 40. Esse processo de industrialização subsequente também desencadeou uma expansão territorial (fig.1), principalmente na região denominada Miolo, onde localiza-se o Cabula.

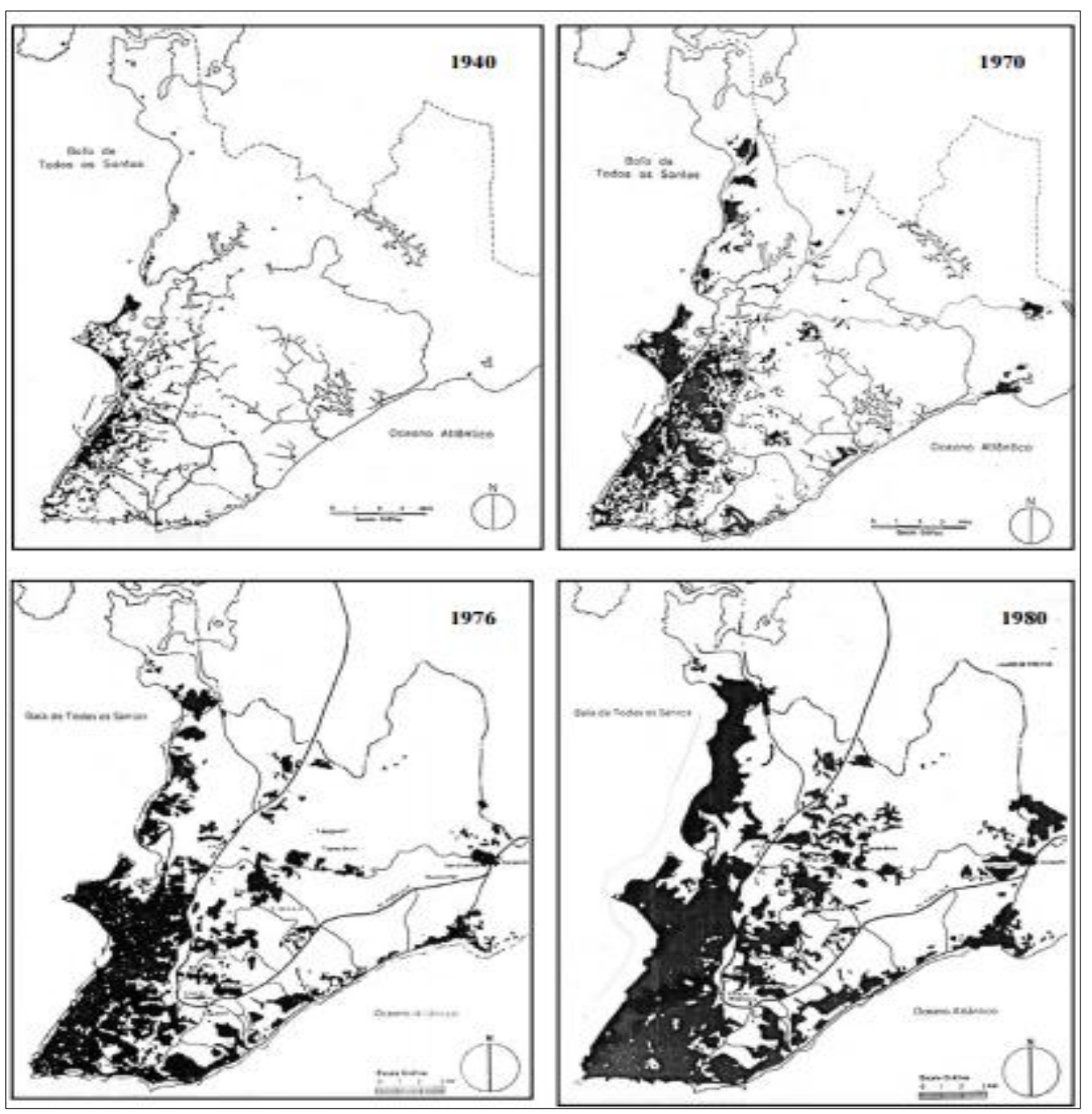

Fonte: Gordilho-Souza, 2000.

Fig. 1- Evolução da Mancha Urbana de Salvador, 1940-1980

Quadro fatores foram propulsores para a expansão horizontal da cidade: crescimento populacional, o desenvolvimento da cidade e a forte especulação imobiliária. Todos os fatores estão diretamente 
relacionados com o aquecimento da economia em Salvador, já que com as oportunidades de trabalho ocorreu a migração das pessoas para a cidade, a necessidade de espaço fez com que para moradia e empresas fez com que a procura por solos baratos se intensificasse e o desenvolvimento do sistema de transporte propiciou que pessoas pouco favorecidas tivessem oportunidade de obter uma moradia em locais mais afastados e com melhores preços

A partir da figura 1, nota-se que o crescimento em meados da década de 70 sob dois principais eixos, a Avenida Luís Viana e a rodovia BR-324. Esse acontecimento se deve a retomada da questão do planejamento da cidade com o Plano de Desenvolvimento da Cidade do Salvador (PLANDURB), favorecendo assim a aceleração do processo de ocupação.

A construção e pavimentação da rua Silveira Martins, principal via do Cabula, pois as áreas ocupadas pelas chácaras e o 19 Batalhão dos Caçadores (1943) passou a receber intervenções do Estado com a construção de conjuntos habitacionais e empresas públicas. Essas intervenções do governo atraíram diversos serviços, como o aumento das linhas de ônibus, empreendimentos comerciais e serviços públicos e privados.

Foram construídos 34 conjuntos habitacionais, até início dos anos 2000, com o total de 9.935 unidades para atender a população com média e baixa renda. Entretanto, segundo Fernandes et al (2005), foi registrado a presença de invasões na região do Miolo, onde se situa o conjunto ora estudado, entre 1968 e 1974, devido ao aumento do custo das terras urbanas.

A alteração do padrão na tipologia habitacional do Cabula, a partir dos anos 200 , começam com a produção de residenciais que são fisicamente isolados por muros a título de segurança. Segundo Caldeira (2000), verdadeiros enclaves fortificados que oferecem a infraestrutura de lazer para seus moradores segregando no meio externo, como se fossem o suficiente para uma vida urbana saudável.

Inserido nessa construção espacial está o Conjunto habitacional Baía de Todos os Santos, também conhecido como Conjunto dos Oficiais da Polícia Militar - 1 (CHOPM-1), construído em 1980 para atender os associados à corporação, entretanto, desde o início existe a comercialização desses imóveis e atualmente quase não moram os associados.

O projeto composto com 55 prédios, uma área de recreação, área escolar, área de entretenimento e dois centros comunitários. O conjunto é delimitado ao norte pela comunidade da Baixinha de Santo Antônio, ao sul pela rua Silveira Martins, ao leste pelo Residencial Reserva Atlântica 1 e ao oeste pela Loja Americanas e Luís Eduardo Magalhães.

Alguns moradores relataram algumas transformações no CHOPM-1 tais como a ligação da Rua Tenente Valmir Alcantara com a Avenida Luís Eduardo Magalhães que favoreceu a implantação de serviços, como limpeza pública e o módulo policial. As áreas recreativa e escolar foram ocupadas pela comunidade próxima, a comunidade da Baixinha de Santo Antônio, fazendo com que algus moradores ocupassem o espaço da obra embargada do Canal 7 de televisão (fig.2). 


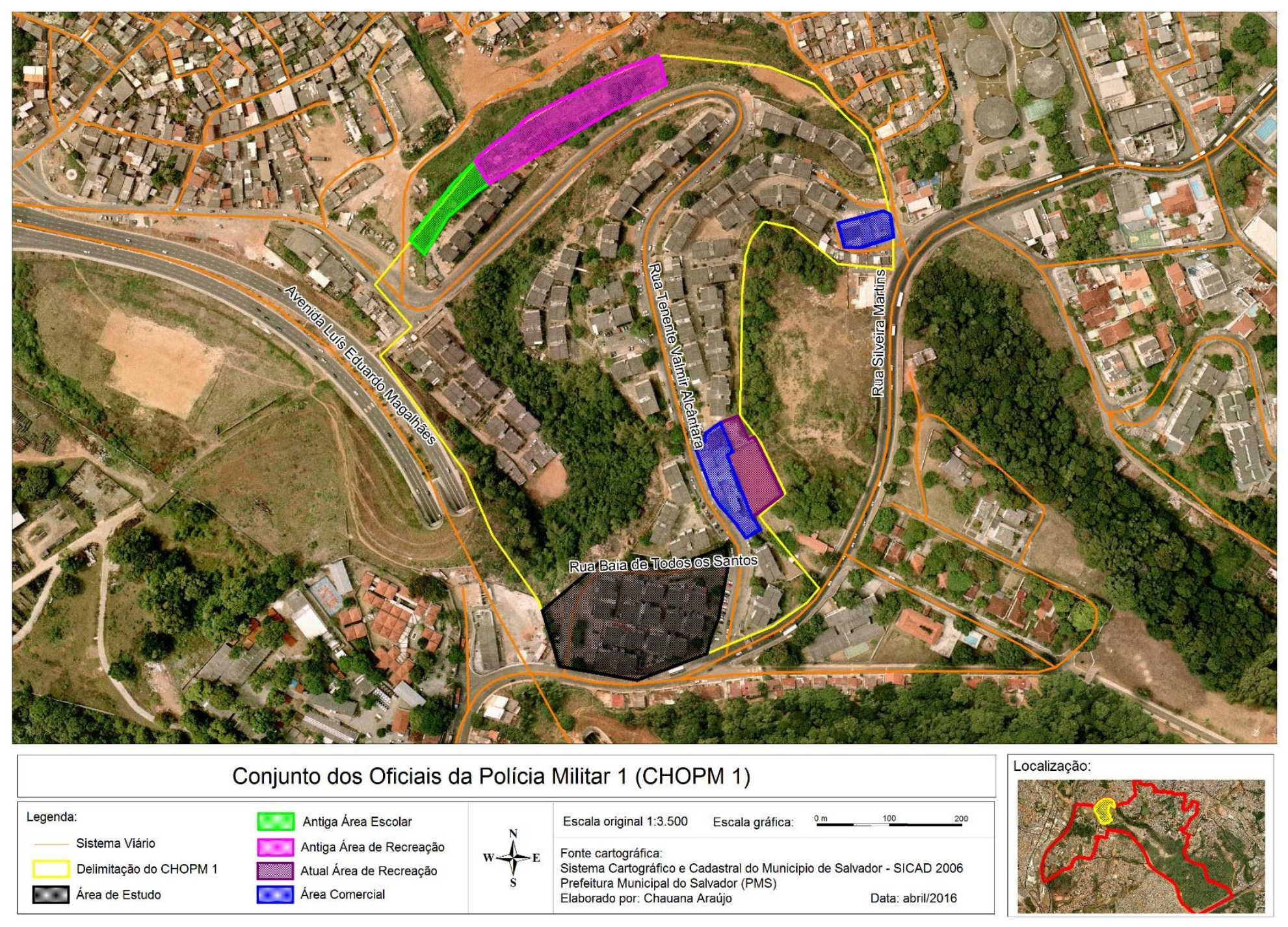




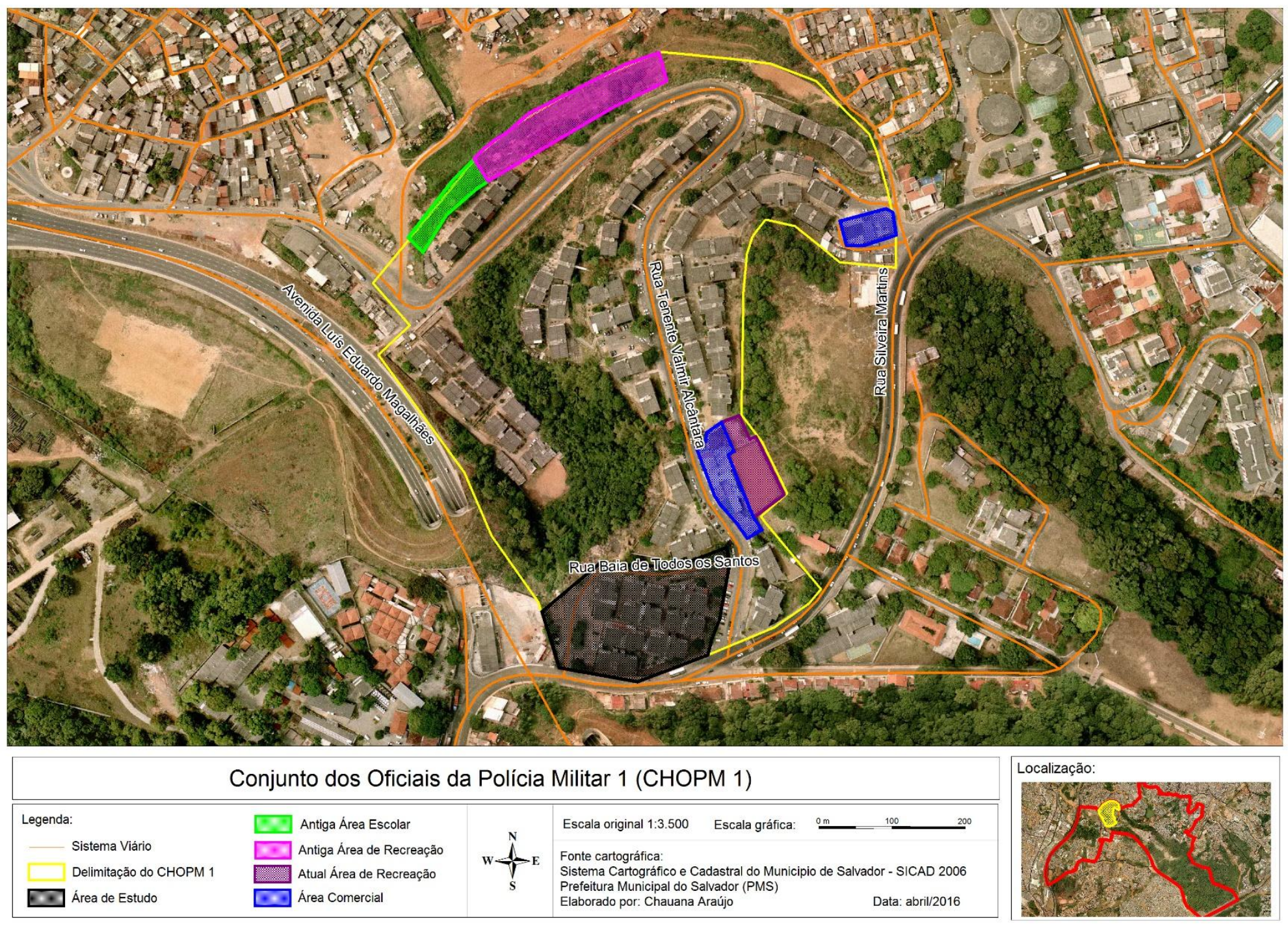

Fig.2 - Mapa do Conjunto dos Oficiais da Polícia Militar- 1 
Compreendendo o contexto do conjunto habitacional e do bairro, analisaremos as transformações morfológicas do espaço comum do bloco 83, área de estudo, buscando compreender os impactos na dinâmica de uso por parte das crianças e adolescentes do conjunto ao longo dos anos. Esse resgate foi possível a partir de conversas com moradores e ex-moradores, experiências próprias e visita de campo.

As duas primeiras décadas do bloco foram marcadas por reformas estruturantes no bloco 83, já que foram criados novos acessos para veículos e escadarias e a praça através de ações coletivas dos próprios moradores. A utilização de carro por parte dos moradores do Cabula era extremamente baixa, o que favorecia a utilização da rua secundárias do conjunto para recreação. As crianças e adolescentes utilizavam dos espaços entre os prédios (fig.3), da praça, estacionamento para realizar as brincadeiras de ruas, conversar. Segundo moradores, o espaço atrás do bloco 83-F foi equipado por traves e demarcações por alguns jovens da época.

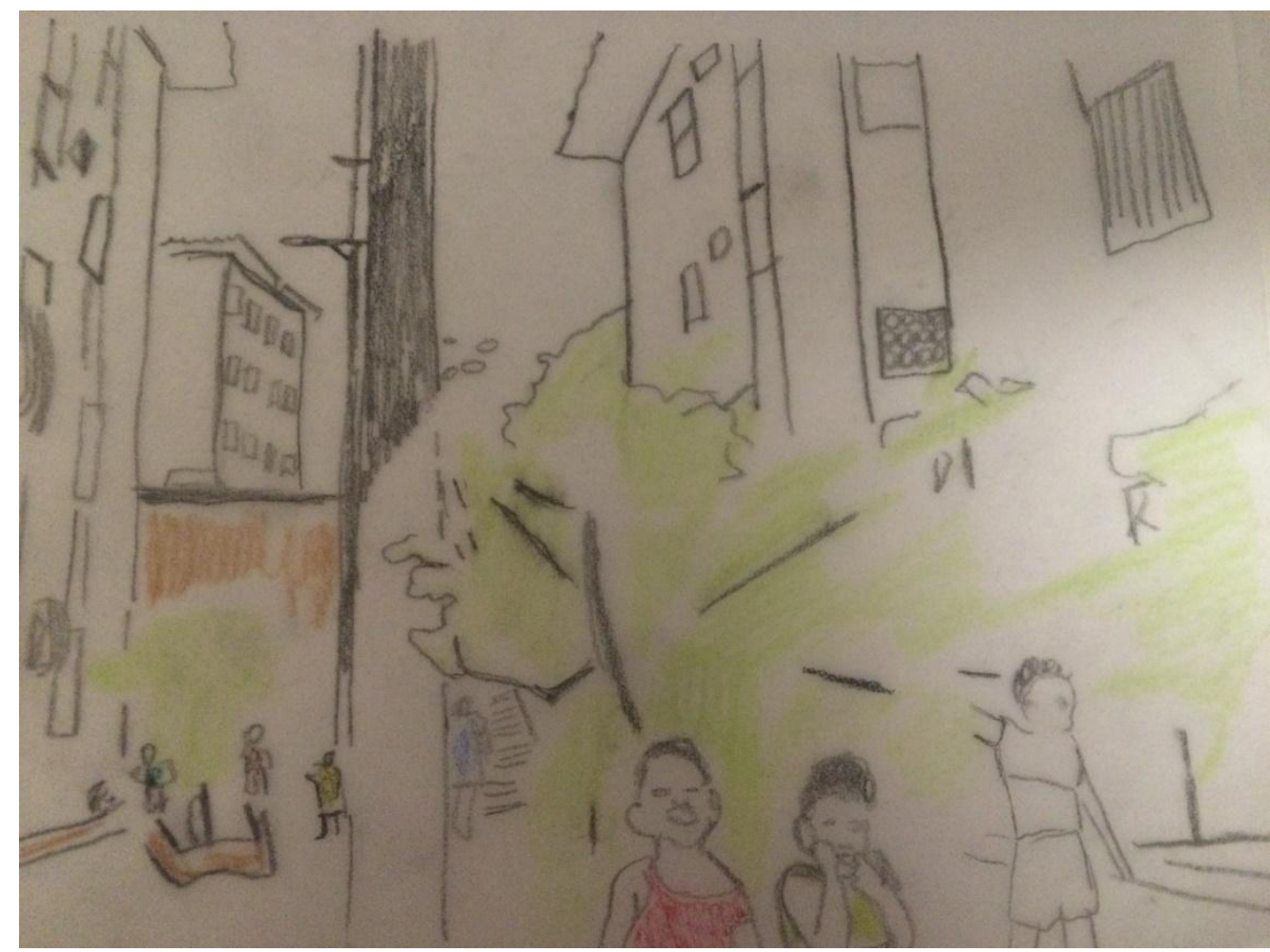

Foto: Elaborado pela autora (2016).

Fig.3-- Croqui a partir de uma fotografia de 1992 entre o prédio 83F e 83G

Alguns moradores que tinham automóveis costumavam estacionar em frente ou próximo a sua janela, entretanto, muitos condôminos que não aceitavam a situação, por conta das crianças do conjunto, foram construindo pequenas jardineiras, bancos com estrutura de concreto e colocando pickets (Fig.4 e 5) para proporcionar mais segurança quanto a acidentes, como também a humanização da área. Com a construção dessas barreiras arquitetônicas os motoristas começaram a concentrar os poucos automóveis existentes na ladeira de acesso ao conjunto e no fundo dos blocos. 


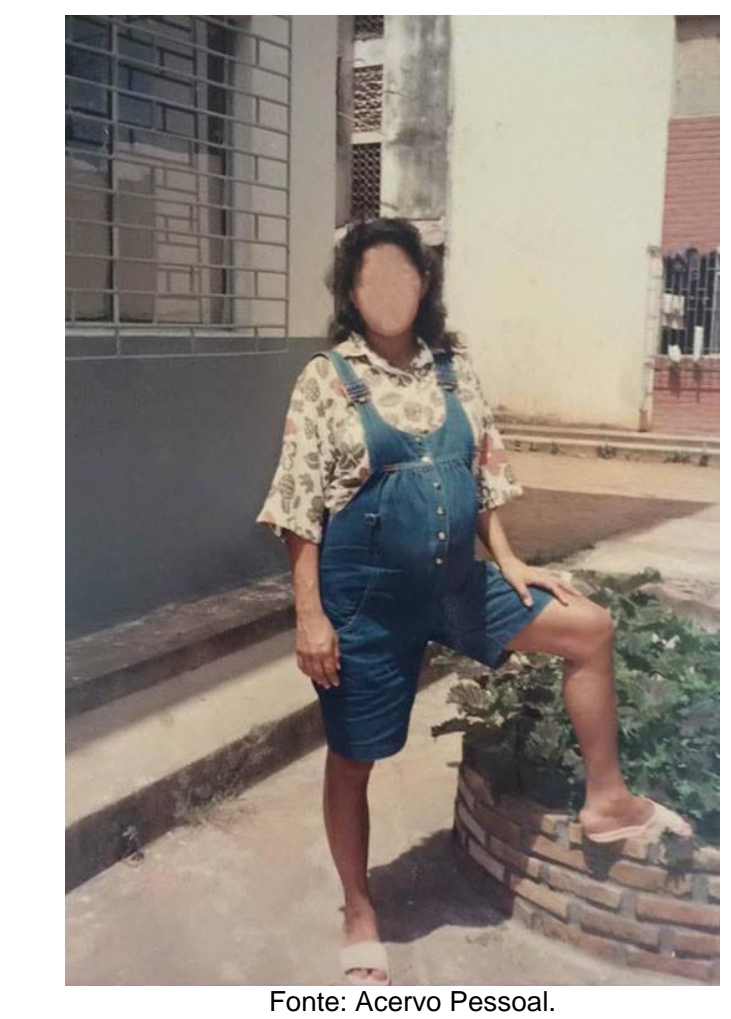

Fig.4 - Fotografia do espaço do conjunto com a jardineira $-1991$

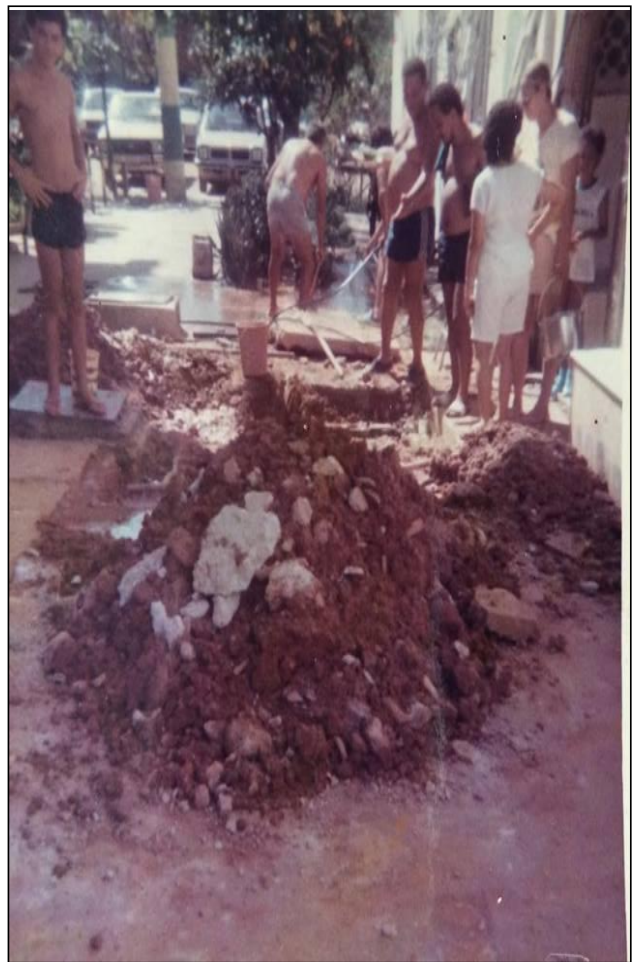

Fonte: acervo pessoal.

Fig.5 - Fotografia do conserto do tanque - 1986

Na década de 90 ocorreu um acidente com um carro que estava trafegando na Rua principal, a Silveira Martins, e caiu dentro da área do conjunto. Este fato cuminou na construção de dois muros que faziam fronteira com essa rua. O crescimento do número de veículos motorizados também contribuiu negativamente na utilização do conjunto.

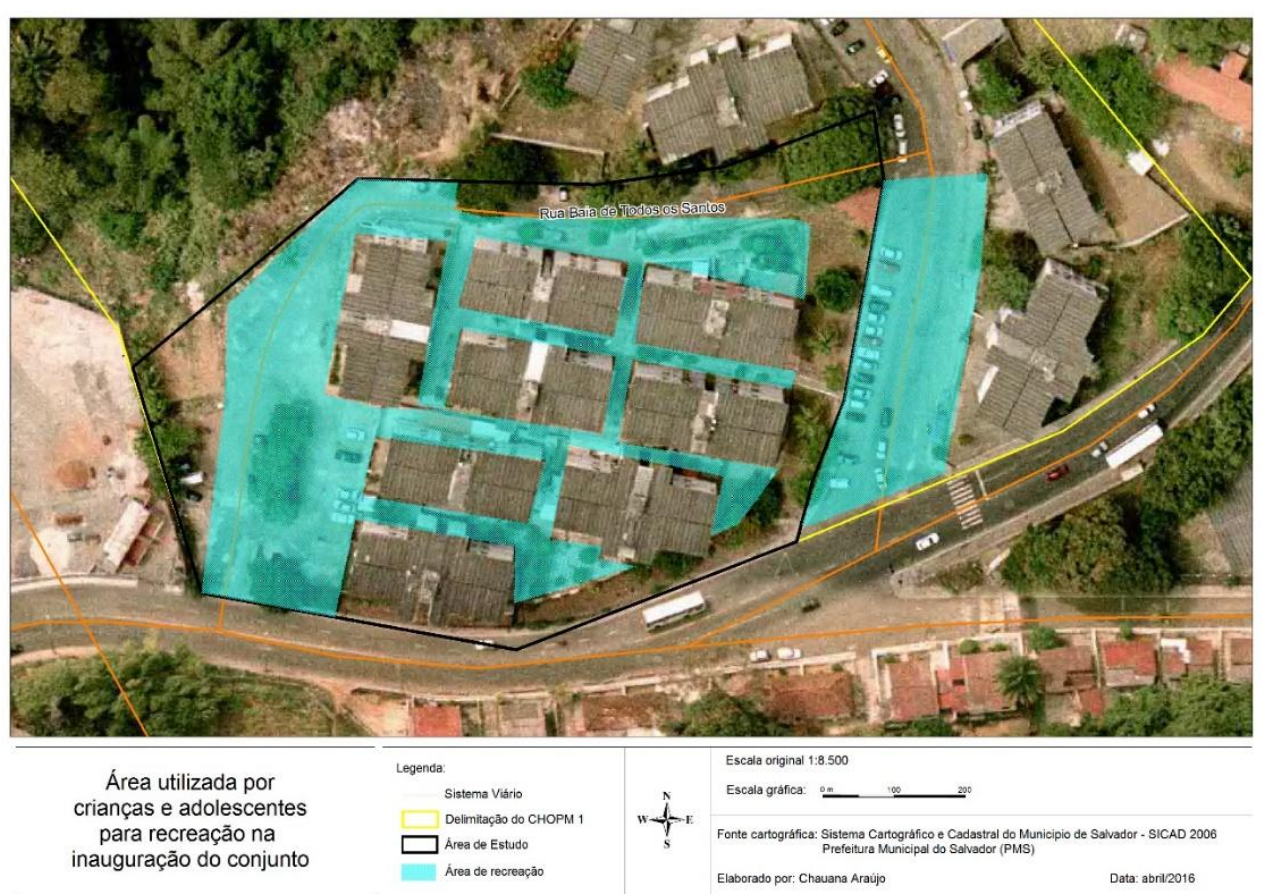

Fig.6 - Área utilizada por crianças e adolescentes para recreação no ano de 1980 e início dos 1990 
De acordo com pesquisas realizadas por Apolinário (2010), Salvador, em meados da década de 90, sofreu um aumento significativo no número de roubos e furtos. Nesse cenário de violência se faz presente também a alteração da morfologia com a construção dos primeiros muros no bloco, inicialmente com visibilidade para o meio externa, porém depois da primeira década do século XXI, alguns muros passaram a ser fechados como puxadinhos e sem visibilidade para o meio externo.

Esses artifícios arquitetônicos ao mesmo tempo que cumpre a função de proteger, dificulta a visibilidade e integração da e com a cidade. Jacobs (2000) alerta sobre a necessidade de olhos para rua, defendendo que os edifícios devem estar voltados para o meio externo, evitando paredes cegas para o espaço público. A recomendação é sustentada pois essas paredes são lugares mais propícios para à incidência de ações violentas. Diante do exposto, analisaremos as alterações morfológicas do bloco 83, no período de 2000 a 2016, atendando as suas a interferência na vitalidade dos espaços comuns

A experiência em campo aliada as vivências anteriores e conversa com moradores nos fez compreender o quando o medo generalizado e os muros inibem a utilização dos espaços públicos. Segundo o morador $x$ (2016):

Os muros foram erguidos, tornando os locais que antes eram abertos em grandes becos, assim deixando as pessoas que chegam do trabalho desprotegidas, pelo simples motivo de que não é possível saber quem pode estar na esquina do muro aguardando a sua chegada. Totalmente diferente de épocas atrás, em que os espaços eram abertos e a sensação de segurança era melhor, pois era possível ver tudo o que ocorria pelo condomínio.

[...] Era de costume ficarmos nos passeios dos prédios, brincando entre os espaços vagos, as pessoas mais velhas se reuniam para conversar durante a tarde e observar as crianças enquanto brincávamos, enfim, tínhamos muita área de lazer, sem limitações.

A praça do conjunto (fig.7 e 8), comumente conhecida como prancinha, era o local mais utilizados pelos moradores de diversas faixas etárias, foi palco de brincadeiras infantis até jogos com os mais idosos, além de ser utilizada por alunos de colégios públicos próximos. Apesar de ter muros, eles permitiam os "olhos na rua " por parte dos moradores. Entretanto, atualmente a conexão com a rua foi fechada e a maioria dos moradores que cercam a praça ergueram muros sem visibilidade. Os pais não descem mais com as crianças e os adolescentes evitam utiliza-la, pois não se sentem seguras.

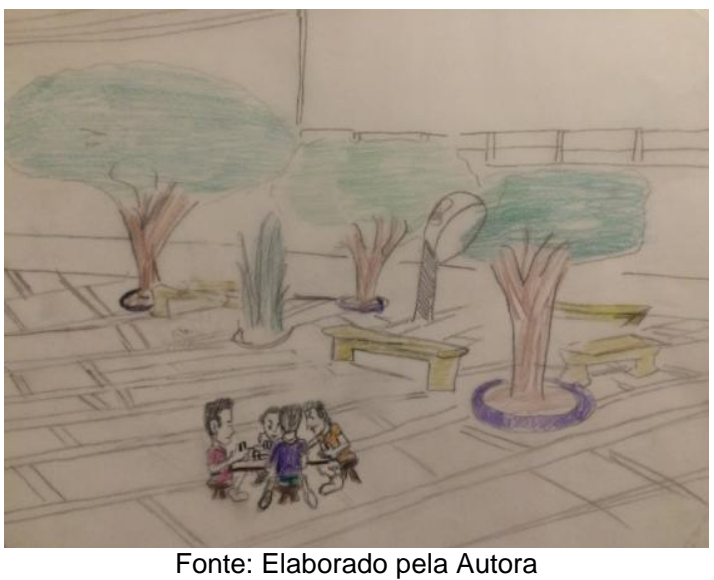

Fig.7 - Croqui da pracinha em 2000

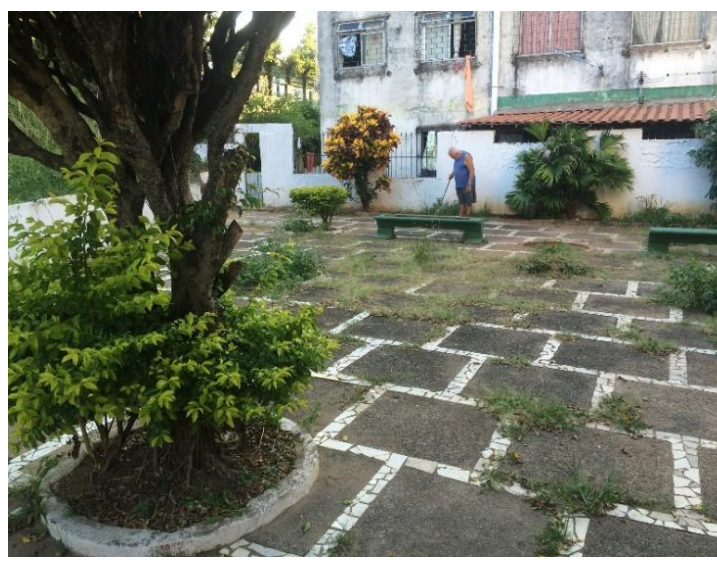

Fonte: Elaborado pela Autora

Fig.8- Fotografia da pracinha 
A frente dos prédios que não cercavam a pracinha também era apropriada por crianças e adolescentes que buscavam desenvolver atividades recreativas ou diálogos, pois tinha bastante espaço, árvores e bancos. Os espaços de uso coletivos eram diariamente utilizados para jogos, celebrações e confraternização, conforme pode ser visto na fig.3.

Um dos prédios era utilizados para recreação até a construção do muro de uso coletivo, este foi construído na ocasião da reforma do reservatório de água. O espaço de uso coletivo foi suprimido com a criação do espaço privativo deste prédio.

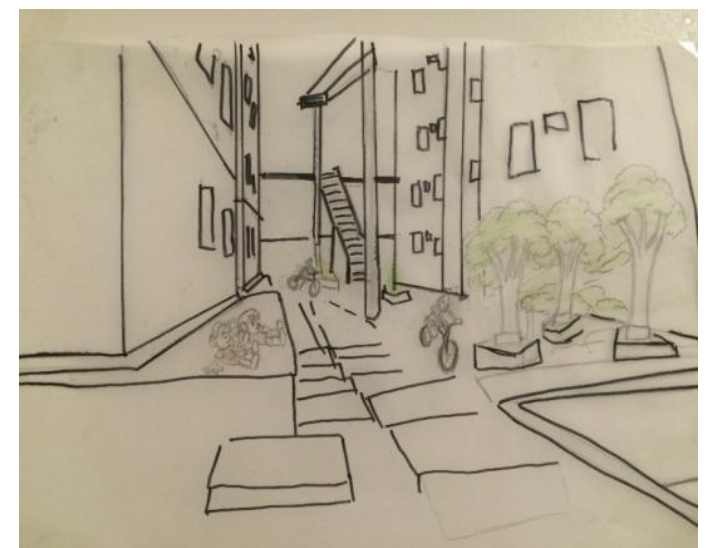

Fonte: Elaborado pela Autora

Fig.9- Croqui da utilização entre os prédios

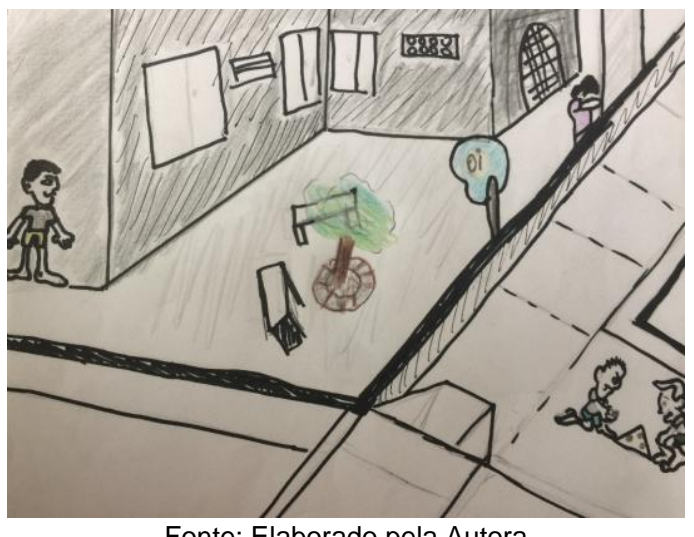

Fonte: Elaborado pela Autora

Fig.11- Croqui da utilização entre os prédios 2

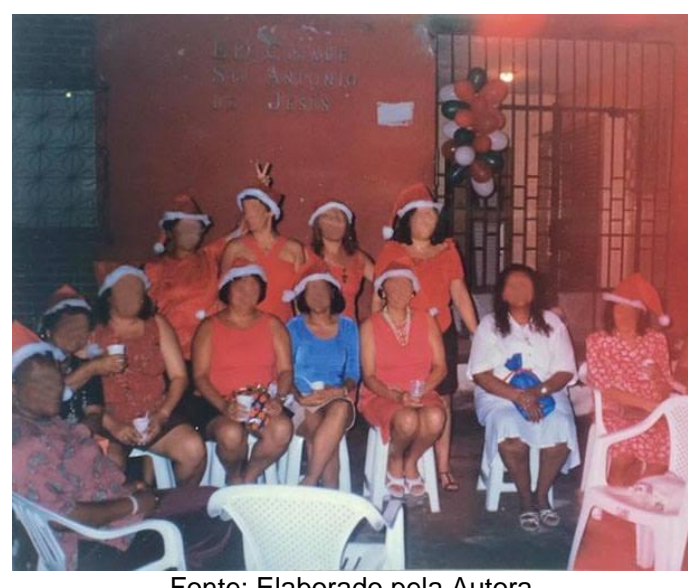

Fonte: Elaborado pela Autora

Fig.10- Confraternização de natal

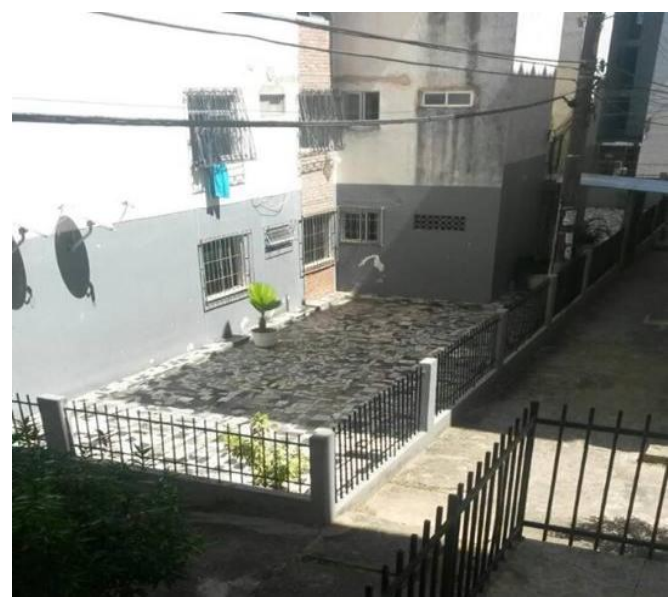

Fonte: Elaborado pela Autora

Fiq.12- Fotoqrafia dos espacos

No campo construindo por alguns jovens, atrás prédio 83F (fig.11 e 12), foi fechado por grades e construído um jardim privado, comprometendo significativamente o espaço de convívio. Nesse espaço eram realizadas atividades esportivas e campeonatos, frequentemente os jovens faziam manutenções. 

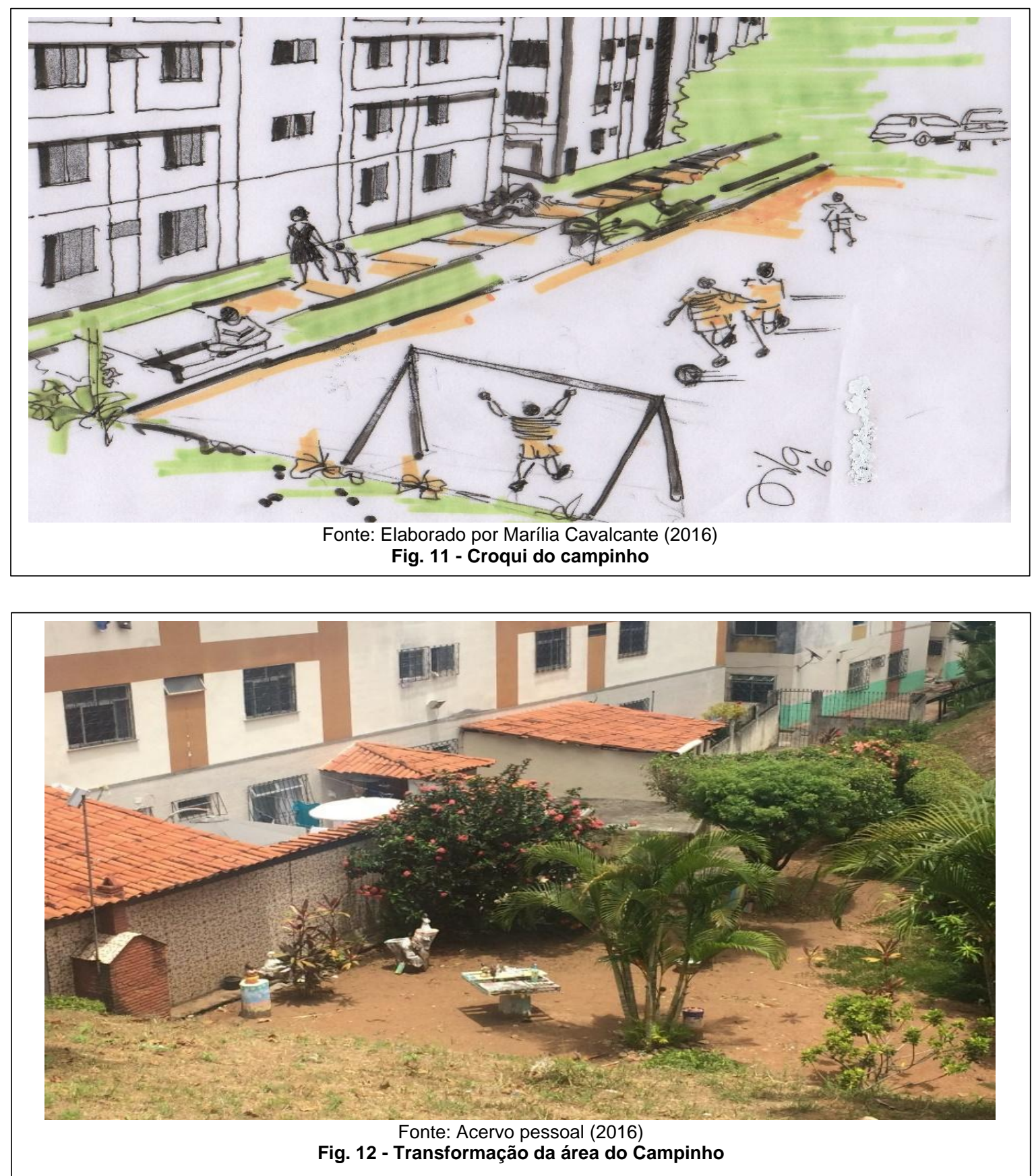

Um morador com apoio financeiro de outras familias idealizou um campo no estacionamento para poder atender as necessidades de recreação, frente à ocupação do campinho para jardim. Entretanto, nos últimos 3 anos essa área começou a ser utilizada para estacionamento de carros. 


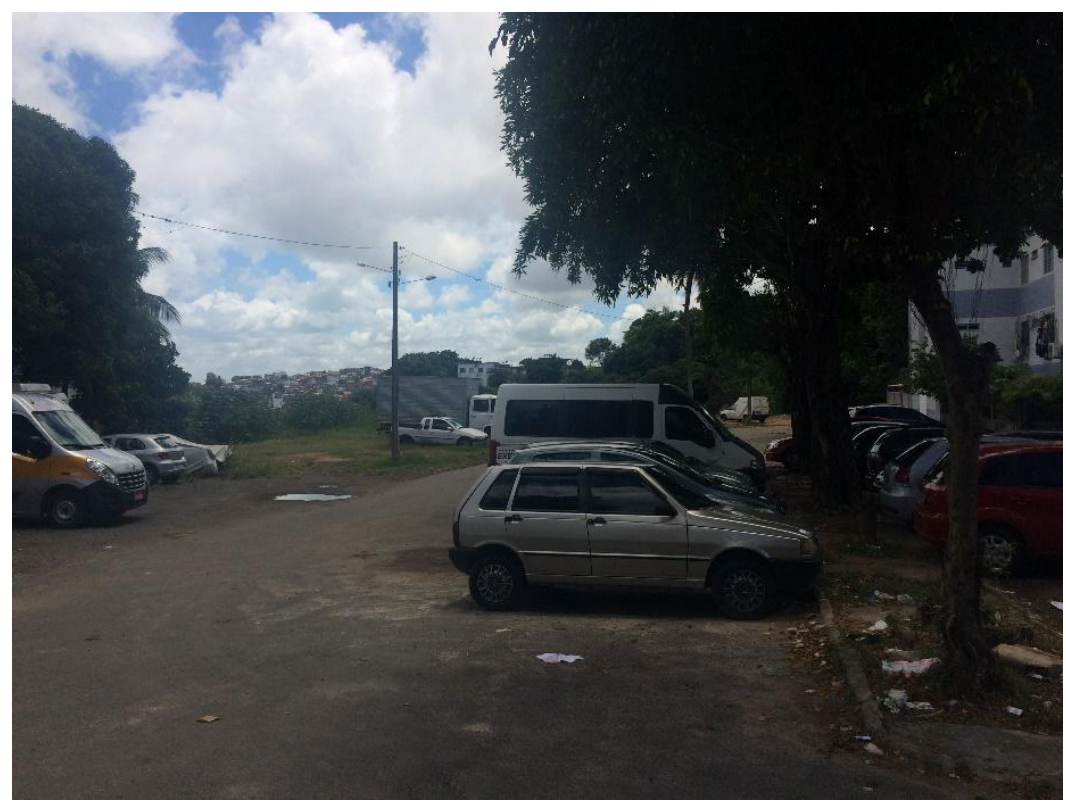

Fonte: Acervo Pessoal (2016)

Fig.13- Fotografia do Estacionamento

É notável que a ocupação dos espaços do bloco 83 interferiu na convivência e também contribuiu para a degradação das atuais áreas comuns. Durante as conversas realizadas com os moradores é possível escutar o barulho de crianças, entretanto, as mesmas não estão nas áreas de convivência e sim confinadas em suas casas. Pequenos espaços formados entre os muros e a pequena praça que restou das modificações do espaço ao longo do tempo são os lugares que podem ser utilizados para o lazer infantil (fig.14).

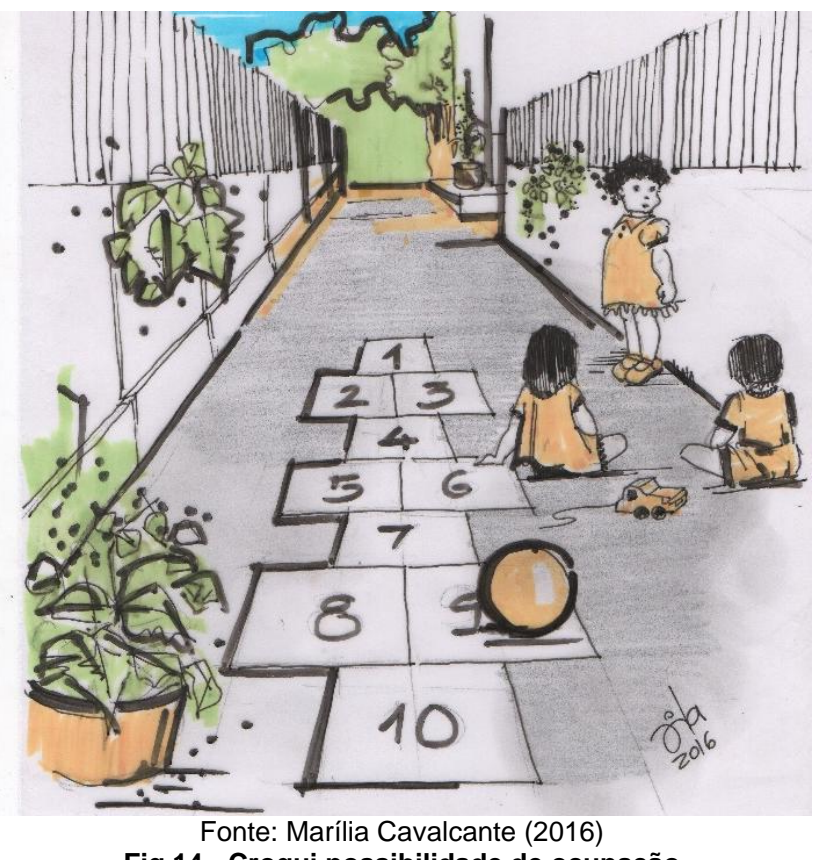

Fig.14 - Croqui possibilidade de ocupação

O bloco 83 do CHOPM-1 foi marcado por destacado por muitos moradores e ex-moradores por ter sido palco da construção de valores que contribuíram para o desenvolvimento como ser humano. Dentre os moradores há uma divisão de opinião sobre o quesito segurança, entretanto, todos abordam como as áreas comuns tornaram-se apenas local de passagem sem vida. Alguns adolescentes relataram que atualmente eles utilizam a área do bloco 182 para conversar, pois se sentem mais seguras e confortáveis. 


\section{CONSIDERAÇÕES FINAIS}

Constatamos assim que, a partir de observações ao longo da vivencia de uma das autoras, Chauana, elementos morfológicos existentes em cada momento e ligando aos aspectos sociais mudanças no espaço e consequentemente no modo de vida de seus moradores, que trouxeram o isolamento das diversas famílias entre si, assim, compreendemos que a morfologia urbana contribui para o entendimento da paisagem e para identificação dos agentes transformadores do espaço.

O medo da violência e da criminalidade revelou-se cada vez mais como um fator estruturante do espaço público e das práticas e vivências de seus habitantes, bem como a utilização do automóvel e a priorização do espaço para sua utilização, mais uma vez expulsa de forma perversa o morador dos espaços concebidos para o lazer, a sociabilidade, e consequentemente desqualificando o local, reduzindo a qualidade de vida do cidadão comum. A maneira como que ocorreu o processo de expansão e desenvolvimento da cidade do Salvador, favoreceu a segregação sócio-espacial.

O trabalho focalizou em evidenciar como o medo generalizado influenciou na transformação e na vivência do bloco 83 do CHOPM - 1. As crianças e os adolescentes foram os protagonistas desta pesquisa, analisandoos como sujeito ativos de ocupação e apropriação para fins de recreação.

Os relatos e vivências permitiram evidenciar que o bloco foi utilizado e apropriado por diversas gerações, entretanto, nos últimos anos percebe-se que a redução dos espaços livres para brincar e socializar, fazendo com que a presença dos moradores nas ruas seja rara.

O interesse individual, baseado inicialmente na cultura do medo, aparece como sujeito desagregador do tecido social. Diante do exposto conclui-se que a violência e o crescimento do número de automóveis privados dado a deficiência do transporte públiço é um fator de transformação do espaço e uma condicionante do empobrecimento das reações sociais. É preciso desenvolver ações de identidade coletiva que visem inspirar as diversas formas de uso e apropriação deste espaço, minimizando os fatores que impedem a apropriação, e consequentemente, pretendendo melhorar a convivência dos moradores e, principalmente, as crianças e adolescentes, assim como políticas públicas que repensem o modelo de cidade atual que fortalecendo a cidadania diante de um processo perverso de urbanização.

\section{REFERÊNCIA}

Gouveia, Anneza. Um olhar sobre o bairro: aspectos do Cabula e suas relações com a cidade de Salvador. Universidade Federal da Bahia,2010.

FERNANDES, R. B.; REGINA, M.E. A segregação Residencial em Salvador no contexto do Miolo da Cidade. Caderno do Logepa - Vol.4, n.1, P.39-46, 2005

CALDEIRA, Teresa P. do Rio. Cidade de Muros: Crime, Segregação e Cidadania em São Paulo. São Paulo: Editora 34, 2000.

APOLINÁRIO, J. S. Criminalidade nas Cidades Centrais da Bahia. Universidade Salvador, 2010.

JACOBS, Jane. Morte e vida de grandes cidades. São Paulo: Martins Fontes, 2000. 